\title{
TEMAS CONTROVERSOS- EDUCAÇÃO AMBIENTAL-FLORESTA: QUAL É A INTERAÇÃO DESTA TRÍADE NO CONTEXTO ESCOLAR?
}

\author{
Aline de Gregorio ${ }^{1}$ \\ Anderson de Souza Moser ${ }^{2}$ \\ Elocir Aparecida Corrêa Pires ${ }^{3}$ \\ Ana Lúcia Olivo Rosas Moreira ${ }^{4}$
}

Resumo: Este trabalho investigou as concepções de Educação Ambiental (EA), além das possíveis interações entre temas controversos e floresta para a inserção de controvérsias socioambientais no contexto escolar, durante um processo de formação continuada com professores da educação básica. Trata-se de uma pesquisa qualitativa, na qual adotou-se a modalidade de pesquisa participante. A coleta de dados se deu por meio da aplicação de questionário. Os resultados evidenciaram o predomínio de concepções conservadoras de EA. Os docentes, que apresentaram visões próximas à vertente crítica, propuseram possibilidades mais abrangentes no que se refere à inclusão de controvérsias socioambientais no desenvolvimento de suas práticas educativas.

Palavras-chave: Formação de Professores; Controvérsia; Problemáticas Socioambientais; Cidadania.

Abstract: This research investigated the Environmental Education (EE), as well as the possible interactions between controversial themes and the forest for the inclusion of social-environmental controverses in the school context, during a continuous education process with the basic education teachers. This is a qualitative research in which we adopted the participative research modality. The data were collected by a questionnaire. The results showcased the predominance of conservatory conceptions of the EE. The teachers with visions closest to the critical aspect proposed broader possibilities to include social-environmental controversies on the development of their educational practices.

Keywords: Teachers Education; Controversy; Social-Environmental Problematic; Citizenship.

\footnotetext{
${ }^{1}$ Universidade Estadual de Londrina. E-mail: alinebio130@gmail.com. Link para o Lattes: http://lattes.cnpq.br/9045854327611151

2Universidade Federal do Paraná. E-mail: anderson_moser@live.com. Link para o Lattes: http://lattes.cnpq.br/2713561914423527

3Universidade Estadual de Maringá. E-mail: lupetrie10@hotmail.com. Link para o Lattes: http://lattes.cnpq.br/6291984361344107

${ }^{4}$ Universidade Estadual de Maringá. E-mail: alormoreira@gmail.com.

Link para o Lattes: http://lattes.cnpq.br/3227131664005073
} 


\section{Introdução}

A autonomia de pensamento, a criticidade e a tomada de posição diante de questões decisórias são indispensáveis para a vida em sociedade e o desenvolvimento de uma nação. Para tanto, é imprescindível um projeto educacional com vistas à formação de sujeitos preparados para o exercício pleno da cidadania.

Ao encontro dessa necessidade, a abordagem de temas controversos no contexto escolar pode contribuir para a formação de cidadãos conscientes e preparados para cumprir o papel que lhes cabe como integrantes de uma sociedade democrática. Além disso, pode suscitar valores como a tolerância e o respeito, que são indispensáveis para a vida em comunidade.

De acordo com Rudduck (1986, p.8, apud REIS, 2007, p.128), um determinado assunto pode ser entendido como controverso se "as pessoas se encontram divididas sobre ele e se envolve juízos de valor que impossibilitam a sua resolução apenas através da análise das evidências ou da experiência". Trata-se de temas em aberto, que dividem opiniões e que requerem debates, discussões e argumentação para que sejam compreendidos podendo ou não chegar a um consenso.

Tendo em vista a complexidade de fatores que podem estar envolvidos em uma controvérsia, para a sua resolução, os sujeitos devem recorrer aos conhecimentos adquiridos ou à busca de novos saberes, a fim de subsidiar 0 posicionamento adotado sobre o tema.

Em razão de suas contribuições, os movimentos para a inserção de temas controversos no contexto escolar têm conquistado destaque. No que se refere aos estudantes, Reis (1999) aponta que a abordagem desses temas contribui significativamente ao estímulo e ao desenvolvimento do pensamento crítico, à tomada de decisão, à capacidade de posicionamento perante situações ambíguas, ao desejo pela busca de novas e melhores fontes de informação e à flexibilidade para a construção de novos conhecimentos.

Salienta-se, ainda, a possibilidade de articulação entre situaçõesproblema do cotidiano aos conteúdos escolares, propiciando um contexto capaz de favorecer o emergir de contradições, interesses, opiniões e confrontos em cenários de contínua transformação.

No entanto, apesar da importância de se trabalhar questões controversas no contexto escolar, as pesquisas têm apontado que essa temática não tem sido abordada com frequência nas aulas, mesmo quando contempladas pelo currículo. Tal fato se deve a aspectos relacionados à própria discussão, aos professores, aos alunos e à organização dos sistemas educativos, que ainda prezam, primariamente, pela preparação dos estudantes para provas e exames, mediante a memorização dos conteúdos (REIS, 2007).

Reis (2007) aponta que temas de natureza controversa se encontram presentes em diversos campos do conhecimento. Como exemplo, podemos citar a política, a economia, a filosofia e a religião. No presente artigo, 
abordamos a temática controversa no âmbito da $E A$, na qual vários são os temas que podem ser considerados polêmicos, tornando-a um campo profícuo para o levantamento de tais questões.

A Política Nacional de Educação Ambiental define a EA como:

[...] processos por meio dos quais o indivíduo e a coletividade constroem valores sociais, conhecimentos, habilidades, atitudes e competências voltadas para a conservação do meio ambiente, bem de uso comum do povo, essencial à sadia qualidade de vida e sua sustentabilidade (BRASIL, 1999, art.1ํ).

Para que essa construção de valores, habilidades e atitudes seja alcançada na prática e em concordância com as orientações das Diretrizes Nacionais Curriculares para a Educação Ambiental - DCNEA (BRASIL, 2012), a EA deve estar inserida no contexto escolar em todos os níveis de ensino de forma crítica e inovadora, visando à construção de uma sociedade consciente e preparada para compreender e agir no que tange às questões ambientais.

Nessa perspectiva, a temática floresta, a partir de Unidades de Conservação, Parques e fragmentos de áreas naturais encontrados em ambientes urbanos, desponta como uma ferramenta que pode auxiliar o trabalho pedagógico. Esses ambientes podem oportunizar discussões das problemáticas ambientais de ordem física e biológica em associação às dimensões social, política, cultural e econômica.

Em complemento a tais aspectos, Scotergana e Negrão (2005) apontam que esses ambientes podem contribuir para a sensibilização ambiental e fornecer meios para que os estudantes integrem conhecimentos específicos aos aspectos socioambientais das florestas, subsidiados por um olhar crítico e multifacetado das questões ambientais.

Para tanto, a qualificação dos professores emerge como ponto fundamental o desenvolvimento de práticas educativas críticas. A elaboração de processos de formação docente deve contemplar, primariamente, a investigação a respeito das concepções de EA que os participantes apresentam, uma vez que o modo como os professores a compreendem influencia diretamente as práticas pedagógicas desenvolvidas em sala de aula (REIGOTA,1995).

Assim, ressalta-se a importância de investigar as concepções que os docentes compartilham sobre a EA, bem como promover momentos para sua qualificação, propiciando condições para que tais concepções possam ser refletidas e ampliadas e, em consequência, resultar em práticas educativas de EA abrangentes e críticas.

Diante do exposto, o objetivo deste trabalho estruturou-se em torno da investigação das concepções de EA de professores da educação básica, bem 
como das possibilidades para a inserção de temas controversos socioambientais no contexto escolar, a partir das interações entre temas controversos, EA e floresta.

\section{Metodologia}

Esta pesquisa se caracteriza como qualitativa. Em consonância com as proposições de Minayo (2002), investigações dessa natureza são motivadas por indagações subjetivas que, para serem respondidas, o pesquisador trabalha com um vasto universo de significados e de intencionalidades que vão sendo incorporados aos atos, às estruturas sociais e às relações humanas, tornando possível a construção do conhecimento.

O desenvolvimento do estudo foi subsidiado pelos pressupostos da modalidade de pesquisa participante, a qual versa sobre as questões socioambientais das relações humanas e tem se consolidado como alternativa metodológica pertinente à condução de pesquisas relacionadas à EA, contribuindo ao fortalecimento da dimensão ambiental na educação (TOZONIREIS, 2005).

O presente artigo compreende o recorte de uma pesquisa de mestrado, em que foi ofertado a docentes da Educação Básica o curso de formação continuada intitulado "Temas Controversos Socioambientais: Abordagens para o Ensino". Cabe ressaltar que o projeto foi submetido e aprovado pelo Comitê Permanente de Ética em Pesquisa com Seres Vivos (COPEP).

Os dados que compõem este artigo são provenientes do questionário inicial, composto por questões abertas e aplicado previamente à intervenção formativa. Por meio desse instrumento de coleta de dados, buscou-se investigar as concepções que os participantes compartilhavam sobre a EA e como poderiam abordar temas controversos a partir da temática floresta nas respectivas práticas educativas. A análise das respostas foi pautada no referencial teórico de Layrargues e Lima (2014), conforme demonstrado no Quadro 1 (próxima página).

Participaram da pesquisa 12 professores, sendo que oito (8) possuem formação na área de Ciências Biológicas, dois (2) em Ciências com habilitação em Matemática, (1) em Pedagogia e um (1) em Geografia. Os professores são atuantes no Ensino Fundamental e Médio, na Educação de Jovens e Adultos EJA, em Curso Técnico em Meio Ambiente e um dos docentes atua como pedagogo escolar.

Para análise e discussão dos dados, visando 0 anonimato dos professores investigados, foram representados pelo código "P" (Participante) seguido do número atribuído a cada um deles como, por exemplo: P1; P2; P3... P12. 
Quadro 1: Macrotendências político-pedagógicas da EA brasileira.

\begin{tabular}{|c|l|}
\hline VERTENTE DE EA & \multicolumn{1}{|c|}{ DESCRIÇÃO } \\
\hline Conservadora & $\begin{array}{l}\text { Pautada nas correntes conservacionistas, comportamentalistas, da } \\
\text { alfabetização ecológica, concebe o ambiente desvinculado das } \\
\text { relações sociais e políticas bem como, dos conflitos de interesses e } \\
\text { de poder. Mergulhada nos princípios da ecologia, compreende o } \\
\text { ambiente como natureza, estando assim, ligada à "pauta verde", } \\
\text { como a biodiversidade, ecoturismo e unidades de conservação }\end{array}$ \\
\hline Pragmática & $\begin{array}{l}\text { Composta por um apanhado das correntes de educação para o } \\
\text { desenvolvimento e consumo sustentável, lança atenção apenas } \\
\text { para a ótica pragmática, deixando de lado a criticidade sobre as } \\
\text { problemáticas ambientais. Está congruente às políticas neoliberais } \\
\text { e de mercado, voltada à "pauta marrom" pelo alinhamento } \\
\text { essencialmente urbano-industrial. Essa vertente concebe o } \\
\text { ambiente como fonte de recursos, e o esgotamento destes, um } \\
\text { problema que precisa ser solucionado ou pelo menos amenizado. } \\
\text { Para isso, são adotadas, na maioria das vezes, ações pontuais não } \\
\text { acompanhadas de reflexão sobre as verdadeiras causas da crise } \\
\text { ambiental. }\end{array}$ \\
\hline Crítica & $\begin{array}{l}\text { Constituída pela união das correntes de EA popular, emancipatória } \\
\text { e transformadora. Objetiva o enfrentamento político e } \\
\text { questionamento das desigualdades de classes e da injustiça } \\
\text { ambiental. Concebe o ambiente sob uma ótica socioambiental, } \\
\text { buscando contextualizar e politizar o debate ambiental. }\end{array}$ \\
\hline
\end{tabular}

Fonte: Layrargues e Lima (2014).

\section{Resultados e Discussão}

Em conformidade com Reigota (1995), o desenvolvimento de abordagens em EA deve ser precedido por uma investigação do modo como os sujeitos envolvidos no processo educativo a compreendem. Assim, as concepções de EA foram investigadas previamente à intervenção formativa. $A$ seguir, serão apresentadas as análises e as discussões empreendidas sobre os dados coletados.

\section{As concepções de EA dos professores}

Dos doze (12) professores investigados, oito (8) apresentaram uma concepção conservadora de EA, dois (2) encaixaram-se na vertente pragmática e dois (2) convergiram à vertente crítica conforme demonstrado no Quadro 2. 
Quadro 2: Formação e concepções de EA dos participantes da pesquisa.

\begin{tabular}{|c|c|c|}
\hline PARTICIPANTE & ÁREA DE FORMAÇÃO & CONCEPÇÃO DE EA \\
\hline P1 & Ciências Biológicas & Pragmática \\
\hline P2 & Pedagogia & Crítica \\
\hline P3 & Ciências Biológicas & Conservadora \\
\hline P4 & Ciências Biológicas & Conservadora \\
\hline P5 & Ciências Biológicas & Conservadora \\
\hline P6 & Ciências Biológicas & Conservadora \\
\hline P7 & Ciências Biológicas & Pragmática \\
\hline P8 & Ciências Biológicas & Conservadora \\
\hline P9 & Geografia & Conservadora \\
\hline P10 & Ciências 1ª Grau Habilitação em Matemática & Crítica \\
\hline P11 & Ciências Biológicas & Conservadora \\
\hline P12 & Ciências $1^{\circ}$ Grau - Habilitação em Matemática & Conservadora \\
\hline
\end{tabular}

Fonte: Os autores (2019).

O discurso de P3 reflete sua concepção conservadora, voltada à conscientização e à preservação, uma vez que o participante concebe a EA como "[...] prática pedagógica voltada a conscientizar sobre as atitudes a serem tomadas em relação ao meio ambiente e sua preservação". Nessa mesma perspectiva, P5 compreende a EA como "[...] ato de educar o ser humano para a aplicação e entendimento da ecologia".

O participante P9 traz, em seu discurso, uma característica clássica da vertente conservadora quando define a EA partindo de características, sobretudo, naturalistas. Segundo seu entendimento, a EA "[...] corresponde ao estudo que se refere ao meio ambiente, relacionando à fauna e à flora."

A macrotendência conservadora se expressa por meio das correntes conservacionista e comportamentalista e da Alfabetização Ecológica. As atividades pedagógicas desenvolvidas focalizam a mudança de comportamento em âmbito individual. É uma tendência histórica, forte e muito bem consolidada, o que pode explicar a forte presença e, por vezes, até a predominância dessa macrotendência sobre as demais (LAYRARGUES; LIMA, 2014).

Dois (2) dos professores (P1 e P7) apresentaram discursos alinhados aos pressupostos da vertente pragmática. Para $\mathrm{P} 1$, a EA é "[...] a compreensão de como se estrutura o ambiente para que as pessoas (cidadãos) possam preservá-lo e atuar de forma sustentável". Para P7, a EA é "[...] ferramentas e/ou estratégias para o entendimento do homem com o meio ambiente visando qualidade de vida".

Percebe-se, na colocação dos participantes, uma preocupação referente à degradação ambiental. Entretanto, essa preocupação se apresenta sob um viés utilitarista e dissociado de reflexões e questionamentos acerca dos modelos de produção e organização da sociedade, contemplando a esfera social, política, econômica e as suas influências no processo de degradação. 
Layrargues e Lima (2014) pontuam duas características da vertente pragmática: a ausência de reflexão que possibilite a compreensão contextual e articulada das causas e consequências dos problemas ambientais e a busca constante por ações pontuais que minimizem os impactos ambientais, visando um futuro sustentável. No entanto, tais ações não superam as fronteiras políticas e econômicas e ficam restritas à conservação.

Dois (2) dos professores investigados apresentaram concepções próximas à vertente crítica. P2 definiu a EA voltada à ação pedagógica, a qual engloba "[...] as abordagens realizadas na escola para que 0 aluno compreenda que ele faz parte do meio ambiente, da fauna e da flora, e que suas ações modificam o meio". A descrição do docente P2 insere o aluno como integrante do ambiente, afastando a visão dicotômica de sociedade e natureza comumente encontrada nas vertentes conservadora e pragmática.

Outro participante com a concepção crítica de EA é P10, que a compreende como:

"[..] respeito aos espaços de convivência entre os seres vivos na biosfera, compreensão do meio ambiente através de estudos científicos comprovados e/ou em processos de mudança. Entender como a ação do homem e sua forma de organização em sociedade também influencia o ambiente" (P10).

O discurso dos dois participantes (P2 e P10) revela uma visão socioambiental, na qual sociedade e natureza estão inter-relacionadas. Para Layrargues e Lima (2014), dois pontos importantes prezados pela macrotendência crítica refere-se à inter-relação entre homem e natureza e à busca pela contextualização e politização do debate sobre as questões ambientais, bem como à problematização das ambiguidades dos modelos de organização e de desenvolvimento das sociedades.

\section{Temas controversos - EA - floresta: possibilidades para inserção de controvérsias nas práticas pedagógicas}

Nesse item, os resultados foram suscitados a partir da análise do questionário referente à seguinte questão: "Como a floresta ou uma reserva natural se insere nos Temas Controversos?". Destaca-se que os participantes P8 e P3 não responderam a essa questão e P12 afirmou não saber.

A partir das análises, emergiram três possibilidades para a inserção de controvérsias socioambientais no contexto escolar por meio da interação entre temas controversos, EA e floresta: (i) explorar os possíveis problemas encontrados nas áreas naturais; (ii) destacar o contraponto progresso versus 
conservação; e (iii) a abordagem socioambiental, envolvendo a floresta e suas dimensões naturais, sociais, políticas e econômicas.

Inseridos na primeira possibilidade estão os participantes P1 e P2, que apontaram a exploração de possíveis problemas que podem ser encontrados nas florestas como oportunidades para a inserção de controvérsias na prática pedagógica. P1 afirma que pode ser possível trabalhar temas controversos com a temática floresta, visto que "esses ambientes estão sofrendo negativamente com a ação do homem". Alinhada a essa possibilidade, desponta a proposta de P2 que afirma ser possível inserir a temática em sala de aula a partir de ambientes naturais "[...] quando há desmatamento/queimadas etc.".

Entretanto, é interessante que a abordagem não inclua apenas o problema por si só, pois há a necessidade de que também sejam apresentadas as causas, as possíveis soluções, as vantagens, as desvantagens e os fatores que possam exercer influência sobre a problemática em pauta. No caso da temática floresta, não se pode deixar de lado as diferentes dimensões que influenciam sua dinâmica e que são amplamente capazes de fornecer elementos para subsidiar as discussões sobre os temas levantados pelos docentes.

A segunda possibilidade teve maior predominância na análise dos dados. Trata-se da exploração do contraponto preservação versus ação negativa do homem no ambiente. P7 destaca a questão do desenvolvimento sustentável, pontuando que uma das formas da floresta se inserir na vertente controversa seria "[...] no entendimento do seu uso e no desenvolvimento sustentável".

Por conseguinte, P6 assinala as discussões relacionadas ao "[...] progresso e desmatamento na contramão da conservação dos ambientes" como oportunidade à inserção das controvérsias. De modo semelhante, P9 propõe o debate sobre "[...] desenvolvimento e preservação". Nesse viés, absolutamente contraditório, de um lado olha-se sob a ótica do progresso, levando em conta questões econômicas e, por outro, as consequências da exploração do ambiente natural.

P4 e P5, ao apresentarem possibilidades para o trabalho de temas controversos, consideraram diversos aspectos. Segundo P4, "como a temática floresta/reserva possui muitos vértices (natural, social, político, econômico), ela pode ser discutida de diferentes pontos de vista, inclusive, conflitantes". A fala da educadora revela um olhar socioambiental sobre a temática floresta. Ao englobar as dimensões social, política e econômica, ampliam-se os espaços para a discussão de diferentes temas sob o viés controverso.

A participante P5 ampliou o repertório das sugestões, destacando que "podemos discutir a necessidade do agronegócio para a produção de alimentos necessitando do desmatamento". A partir dessa fala, é possível denotar que o 
docente vai além dos aspectos naturais que fazem parte do ambiente, ou seja, não pode ser a única dimensão a compor a abordagem pedagógica.

Gayford, Dillon e Scott (2002) destacam que o trabalho com temas controversos exige dos professores o entendimento científico e a compreensão do que seja importante levar para a sala de aula em termos de conteúdo. Complementando esse ponto, Reis (2007) indica que a capacidade de flexibilização do currículo, em consonância com os objetivos de aprendizagem e as particularidades provenientes da realidade de trabalho em que o professor está inserido, são fatores que influenciam na inserção ou na ausência desses temas nas práticas pedagógicas dos educadores.

A intersecção entre as controvérsias e a temática ambiental requer uma articulação de conhecimentos científicos com perspectivas críticas, sem excessivas certezas ou simplificações (RIBEIRO; KAWAMURA, 2014). Assim, se faz necessária a constante reflexão no que se refere às formas de agir e pensar os temas ambientais. Nesse viés, concordamos com Jacobi (2003) quanto à necessidade de que os educadores compreendam a EA de forma crítica e holística, integrando-a em sua prática educativa a partir de uma visão mais complexa do mundo.

\section{Conclusões}

Esse trabalho objetivou investigar as concepções de EA de professores atuantes na educação básica, bem como as possíveis interações entre a tríade temas controversos, EA e floresta. A predominância da concepção conservadora de EA nas respostas dos docentes evidencia a necessidade do desenvolvimento de intervenções formativas que forneçam subsídios teóricos e práticos para a superação da visão ingênua e simplista acerca das problemáticas ambientais.

Quanto às possibilidades de inserção de temas controversos socioambientais nas práticas pedagógicas dos docentes, identificou-se três caminhos: (i) exploração dos possíveis problemas encontrados nas áreas naturais; (ii) abordagem do contraponto progresso versus conservação; e (iii) abordagem socioambiental, envolvendo a floresta e suas dimensões naturais, sociais, políticas e econômicas.

Dentre as possibilidades levantadas, a que leva em consideração a abordagem sob o enfoque socioambiental oferece maiores possibilidades para o levantamento de controvérsias. Isso pode ser justificado pelo fato de que a referida abordagem contempla os aspectos sociais, culturais, econômicos e políticos dos ambientes naturais, possibilitando o surgimento de questões controversas relacionadas às diferentes dimensões que o integra.

Os professores que apresentaram concepções críticas de EA apontaram maiores possibilidades para o levantamento de controvérsias a partir da temática floresta. Desse modo, concluímos que a forma como o docente concebe a EA, reflete em seus encaminhamentos metodológicos, no que se 
refere à inserção de controvérsias socioambientais no desenvolvimento de suas práticas educativas.

Ressalta-se a necessidade de processos formativos que partam de problemáticas presentes no contexto de trabalho dos professores e dos estudantes, que discutam suas possíveis causas, bem como as influências advindas das diferentes dimensões que compõem 0 ambiente. Tais intervenções poderão possibilitar que os educadores ressignifiquem suas compreensões sobre a EA e as controvérsias, de modo que esses dois campos do conhecimento, quando convergirem no trabalho pedagógico, sejam abordados sob o viés socioambiental e pautados em uma perspectiva multifacetada e crítica do ambiente.

\section{Agradecimentos}

Agradecemos à Coordenação de Aperfeiçoamento de Pessoal de Nível Superior (CAPES) pela bolsa concedida, ao Programa de Pós-Graduação em Educação para a Ciência e a Matemática (PCM-UEM) e ao Núcleo Regional de Educação de Maringá, pela autorização, apoio e divulgação do curso de formação continuada.

\section{Referências}

BRASIL. Lei n. 9795 - 27 de abril de 1999. Dispõe sobre a Educação Ambiental. Política Nacional de Educação Ambiental. Disponível em:< http://www.planalto.gov.br/ccivil 03/leis/19795.htm > Acesso em: 02 ago. 2019.

BRASIL. Resolução no 2, de 15 de junho de 2012. Estabelece as Diretrizes Curriculares Nacionais para a Educação Ambiental. Disponível em:< http://portal.mec.gov.br/dmdocuments/rcp002 12.pdf > Acesso em: 04 ago. 2019.

GAYFORD, C.; DILLON, J.; SCOTT, W. Controversial environmental issues: a case study for the professional development of science teachers. International Journal of Science Education, v. 24, p. 1191-1200, 2002.

JACOBI, P. Educação Ambiental, cidadania e responsabilidade. Cadernos de pesquisa, São Paulo, n.118, p. 189-206, 2003.

LAYRARGUES, P. P.; LIMA, G. F. DA C. The Brazilian environmental education macro-politicalpedagogical trends. Ambiente \& Sociedade, v. 17, n. 1, p. 23-40, 2014.

MINAYO, M. C. S. Pesquisa social. Teoria, método e criatividade. 21 ed. Petrópolis: Vozes, 2002.

REIGOTA, M. Meio ambiente e representação social. São Paulo: Cortez, 1995. $87 \mathrm{p}$. 
REIS, P. A discussão de assuntos controversos no ensino das ciências. Inovação, v.12, p. 107-112, 1999.

REIS, P. Os temas controversos na Educação Ambiental. Pesquisa em Educação Ambiental, v. 2, n. 1, p. 125-140, 2007.

RIBEIRO, R.; KAWAMURA, M. R. Educação Ambiental e temas controversos. Revista Brasileira de Pesquisa em Educação em Ciências, São Paulo, v. 14, n. 2, p.159-169, 2014.

SCOTERGAGNA, A.; NEGRÃO, O. B. M. Trabalhos de campo na disciplina de geologia introdutória: a saída autônoma e seu papel didático. Terra e Didática, Campinas, v. 1, n. 1, p. 36-43, 2005.

TOZONI-REIS, M. F. C. Pesquisa-ação. In: FERRARO-JUNIOR, L. A. Encontros e caminhos: formação de educadoras(es) ambientais e coletivos educadores. Brasília: MMA, v. 1, p. 267-276, 2005. 